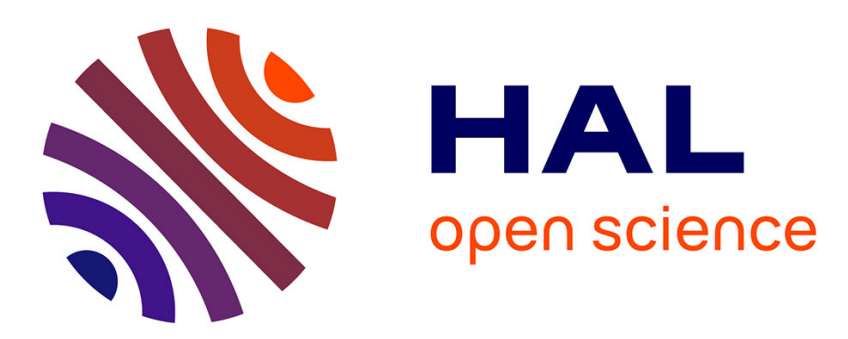

\title{
High intensity picosecond Fourier limited pulses : design of a synchronously pumped dye laser system
}

\author{
G. Petite, P. Agostini, C.K. Wu
}

\section{To cite this version:}

G. Petite, P. Agostini, C.K. Wu. High intensity picosecond Fourier limited pulses: design of a synchronously pumped dye laser system. Revue de Physique Appliquée, 1985, 20 (7), pp.527-530. 10.1051/rphysap:01985002007052700 . jpa-00245366

\section{HAL Id: jpa-00245366 https://hal.science/jpa-00245366}

Submitted on 1 Jan 1985

HAL is a multi-disciplinary open access archive for the deposit and dissemination of scientific research documents, whether they are published or not. The documents may come from teaching and research institutions in France or abroad, or from public or private research centers.
L'archive ouverte pluridisciplinaire HAL, est destinée au dépôt et à la diffusion de documents scientifiques de niveau recherche, publiés ou non, émanant des établissements d'enseignement et de recherche français ou étrangers, des laboratoires publics ou privés. 


\title{
High intensity picosecond Fourier limited pulses : design of a synchronously pumped dye laser system
}

\author{
G. Petite, P. Agostini \\ Service de Physique des Atomes et des Surfaces, CEN/Saclay, 91191 Gif-sur-Yvette Cedex, France
}

and C. K. Wu

Shanghaï Institute of Optics and Fine Mechanics, Academia Sinica, China

(Reçu le 11 janvier 1985, révisé le 12 mars, accepté le 25 mars 1985)

\begin{abstract}
Résumé. - Nous décrivons un montage simple permettant d'obtenir des impulsions laser picoseconde de haute intensité et de faible largeur spectrale satisfaisant aux limites imposées par la transformation de Fourier. L'oscillateur à colorant est pompé de manière synchrone par un laser picoseconde au $\mathrm{Nd}$ : Yag. Après amplification, on obtient des impulsions d'une durée de 20 ps pour une largeur spectrale de $30 \mathrm{GHz}$, avec une énergie pouvant atteindre $1,5 \mathrm{~mJ}$.
\end{abstract}

\begin{abstract}
We present a simple design for obtaining high-intensity, Fourier limited picosecond pulses. A Nd : Yag picosecond laser is used to synchronously pump a dye oscillator/amplifier system. The dye oscillator is of the Littman type. Up to $1.5 \mathrm{~mJ}$ of energy is obtained in a 20 ps pulse with a bandwidth of $30 \mathrm{GHz}$ after amplification.
\end{abstract}

\section{Introduction.}

It has been two decades now since the first picosecond laser was built and there has been a constant interest in such systems ever since. Picosecond pulses are interesting in many respects. First they represent one of the two completely organized states of operation of a laser (together with the single longitudinal mode laser), delivering what is known as a " Fourier limited " pulse. Secondly because ultrashort light pulses are of a very broad interest in many different fields of research, including for instance the study of fast photochemical or photophysical processes. They also provide a source of very high laser intensities while keeping the total energy used in the experiment rather low.

Picosecond light pulses were first obtained by modelocking giant pulse solid state lasers [1]. Most of the work since has dealt with dye lasers [2]. They are tunable throughout all the visible and near IR spectrum and also delivered the shortest light pulses, down to the hundred femtosecond range. Shortest pulses have been obtained using passively mode locked systems, but the first operation of a picosecond dye laser [3] was obtained using synchronous pumping where the gain is impulsively driven at the cavity round trip repetition rate. With both methods, peak intensities of about $1 \mathrm{MW}$ were obtained which though significant is still too low for a good number of applications, particularly in the field of high-order nonlinear processes. Amplification to the $1 \mathrm{GW}$ level of CW based dye lasers has been achieved using a Nd : Yag pumped amplifier system but such systems are unconvenient in many respects : they are expensive and heavy to run and many of the advantages of the $\mathrm{CW}$ based systems are lost (high repetition rate). One also has to face all of the nanosecond dye amplifiers problems in much worst conditions because of the low output level of the dye oscillator.

Here we report a simple design of a Nd : Yag pumped oscillator-amplifier system delivering Fourier limited pulses in the millijoule-per-pulse energy range with a 20 ps duration, which may be of a very broad interest whenever ultrashort laser pulses are not necessary. A similar system has been recently proposed in [4] but ours presents several significant modifications which were found to be essential to obtain Fourier limited pulses.

In the first part of this paper, we describe the main characteristics of our pump laser. We then describe the dye laser-amplifier arrangement. The last part of this paper reports the different tests and measurements of the output characteristics of our system. 


\section{Pump-laser.}

Our pump laser is, except for a few minor modifications, a commercial picosecond $\mathrm{Nd}: \mathrm{Yag}$ system (Quantel). In the oscillator, which is passively mode locked, the original steering cell was changed for a flow cell, resulting in a better stability of the dye solution (Kodak 9740 in dichloro 1,2 ethane). With this configuration the oscillator delivers a train of about 10 pulses whose length can be selected between 30 and 200 ps by changing the output coupler which is acting as a Fabry-Perot. The energy in the train is about $16 \mathrm{~mJ}$, but the shot to shot stability is poor (not better than $10 \%$, with a new dye solution). This can be improved by the use, in addition to the mode locking dye, of an acousto-optic modulator inside the oscillator cavity (placed close to the output coupler, when the dye is flowed close to the rear mirror). This leads to a decrease of the output energy (down to about $8 \mathrm{~mJ}$ per train) but the shot to shot stability is then better than $5 \%$. Beam profile is nearly Gaussian.

At the output of the oscillator, a beam splitter reflects one half of the laser energy which is frequency doubled and used to pump the dye oscillator. The other half is passed through an electro-optical shutter which selects one of the pulses in the train, which is then passed through a two-amplifiers system. The energy in this single pulse which is used, after frequency doubling, to drive two dye amplifiers, is about $40 \mathrm{~mJ}$. After frequency doubling, the available energies at $530 \mathrm{~nm}$ are respectively about $1 \mathrm{~mJ}$ for the dye oscillator, $1.2 \mathrm{~mJ}$ for the first amplifier and $4.5 \mathrm{~mJ}$ for the second amplifier. This pump laser is represented on figure 1 .

\section{Dye laser system.}

After reflection on a dichroic mirror selecting the $530 \mathrm{~nm}$ light, the pumping train is focused in the dye cell of the dye oscillator (as shown on Fig. 2) down to a diameter of a few tenths of a millimeter. Nearly collinear pumping is used. 'The dye solution (rhodamine $6 \mathrm{G}$ in methanol or in ethylene glycol, concentra-

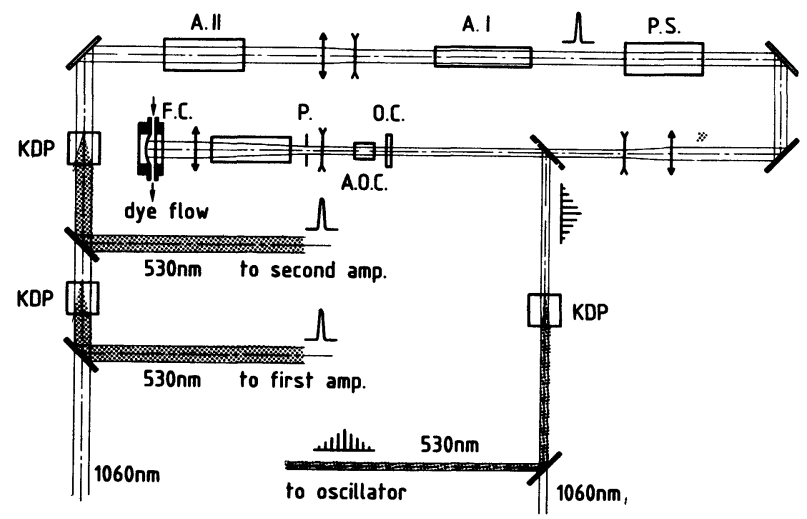

Fig. 1. - Nd : Yag pump laser. F.C. : flow cell; $P$ : pinhole; A.O.C. : acousto-optic modulator; O.C. : output coupler; P.S. : pulse selector; A.I (II) : amplifier I (II).

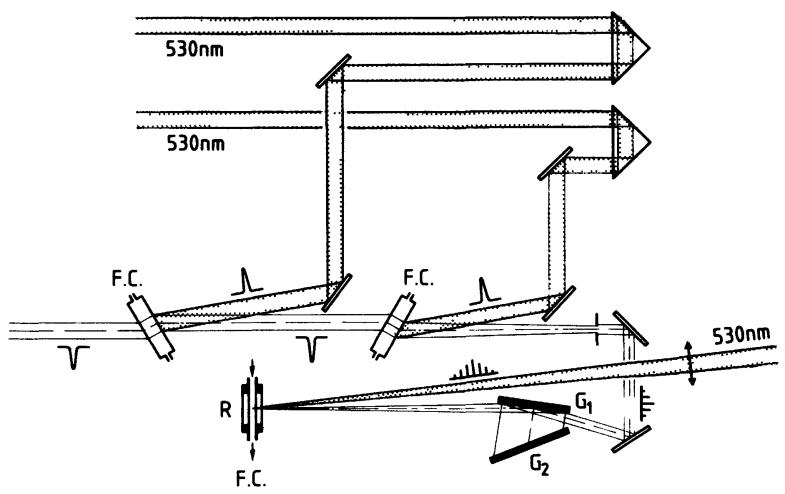

Fig. 2. - Dye laser/Amplifier system. F.C. : flow cells; $\mathbf{R}$ : rear mirror; $\mathrm{G} 1$ : grazing incidence grating; $\mathbf{G} 2$ : Littrow mounted grating.

tion close to $10^{-3} \mathrm{M} / 1$ ) is flowed in contact with the rear mirror $R(100 \%$ reflecting $)$ in a cell similar to that used in the Nd : Yag oscillator, with a thickness of one millimeter. The oscillator is of the Littman type [5], i.e. the wavelength selection is achieved through a double grating assembly. A first grating ( $\mathrm{Gl}$ on Fig. 2 , $2400 \mathrm{gr} / \mathrm{mm}$ ) is used at a high incidence angle $\left(85^{\circ}\right)$, its first order diffracted beam is reflected by a Littrow mounted grating G2 (1 $200 \mathrm{gr} / \mathrm{mm}$, used in the second order). Alternatively a simple mirror can be used instead of grating $\mathbf{G} 2$. Wavelength is adjusted by rotation of G2. The total cavity length (i.e. RG1 + G1G2) is set equal to the length of the pump laser oscillator cavity, so that mode locking of the dye oscillator is obtained by synchronous pumping. The zeroth order of the G1 grating is used as the output. The pump polarization is set linear and perpendicular to the grating plane, which corresponds to the direction of best efficiency for the gratings. This leads to a dye laser beam with the same polarization (in the plane of Fig. 2).

The output of the dye oscillator is a train of 4 to 6 short picosecond pulses with an energy per train of $20 \mathrm{~mJ}$ (for $0.8 \mathrm{~mJ}$ in the pumping train). This pulse train is then passed through a system of two amplifiers longitudinally pumped by the frequency doubled amplified single Nd : Yag pulses. The two amplifiers are $1 \mathrm{~cm}$ long; the dye is flowed with a concentration of about $10^{-4} \mathrm{M} / 1$, adjusted to obtain almost complete absorption of the pump beam. Efficient amplification is obtained only when the pump pulse is present in the amplifier cells together with one of the pulses of the oscillator train. For this reason the pumping pulses are delayed for both amplifiers in adjustable delay lines. Performances of our amplifiers were found to depend very strongly on the length of these delay lines which have to be adjusted within a few millimeters. The output of the first amplifier is a single pulse with an energy of $200 \mu \mathrm{J}$ (when pumped with $1.2 \mathrm{~mJ}$ ). At the output of the second amplifier, up to $1.5 \mathrm{~mJ}$ of energy was measured, for a pump energy of $4.5 \mathrm{~mJ}$ in the second amplifier. 
None of the problems classically encountered in the design of nanosecond amplifier systems were met here. This is simply due to the fact that no lens is used on the dye laser beam which could focus the fluorescence of one of the dye cell into the next one. Another key feature is the pulse shortness (much smaller than the space between two successive stages), and the good temporal coincidence between the pumping and the dye laser pulse in each cell.

\section{Measurements of the laser characteristics.}

The duration of the amplified dye pulse and its spectrum were studied. Pulse lengths were measured using a streak camera, as reported in [6], and spectra were recorded using a $1.5 \mathrm{~m}$ focal length spectrometer with a $10 \mathrm{GHz}$ bandwidth. The influence of the characteristics of the grating assembly on the pulse duration and the spectrum were studied.

We first tried a setup identical to the one described in [4]. Instead of a double grating assembly, a single $(600 \mathrm{gr} / \mathrm{mm})$ Littrow-mounted grating was used. It resulted in an extremely broad spectrum $(660 \mathrm{GHz})$, very irregular and fluctuating. Pulse lengths were not measured in this case, but it is known [7] that in such a case, corresponding fluctuations are in general observed on the pulse shape. Overintensities with a duration of about 1 ps are expected in this particular case, that is shorter than the time resolution of our streak camera ( $5 \mathrm{ps})$. The reason why these fluctuations were not seen in [4] is probably the use of an autocorrelator instead of a streak camera, giving access to an average pulse shape only. Up to a $3000 \mathrm{gr} / \mathrm{mm}$ grating was used resulting in narrower spectra, but still very irregular and fluctuating. Therefore we decided to use a double grating assembly which, when no beam expander is used in the cavity, has a much better selectivity.

Typical results for the pulse shape and the spectrum obtained with the chosen assembly (Grazing incidence grating G1 : $2400 \mathrm{gr} / \mathrm{mm}$, incidence $85^{\circ}$; Littrow mounted grating G2 : $1200 \mathrm{gr} / \mathrm{mm}$, second order) are shown on figure 3. Figure 3 a shows a recording of the pulse shape obtained with the streak camera. The two pulses on this figure are obtained as described in [6] by splitting the dye laser pulse in a Michelson interferometer. One of the pulses is delayed and attenuated by $50 \%$ to provide time and intensity calibration of the streak camera. The measured pulse length is $(20 \pm 5)$ ps with a time resolution of 5 ps. The spectral width, as measured on the spectrum of figure $3 \mathrm{~b}$ (top), is $30 \mathrm{GHz}$ with a $10 \mathrm{GHz}$ resolution. For comparison the bottom spectrum of figure $3 \mathrm{~b}$ has been obtained with a single Littrow mounted grating $(2400 \mathrm{gr} / \mathrm{mm})$ in the cavity, and a spectrometer dispersion reduced by a factor of two. It clearly shows the broadening and fluctuations mentioned above. With our final setup, we obtain a time-bandwidth product

$$
\Delta v \times \Delta t=0.6 .
$$

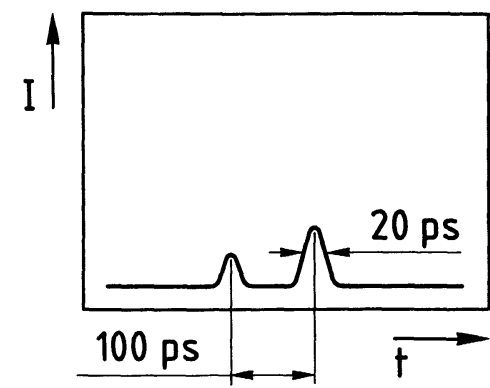

a)

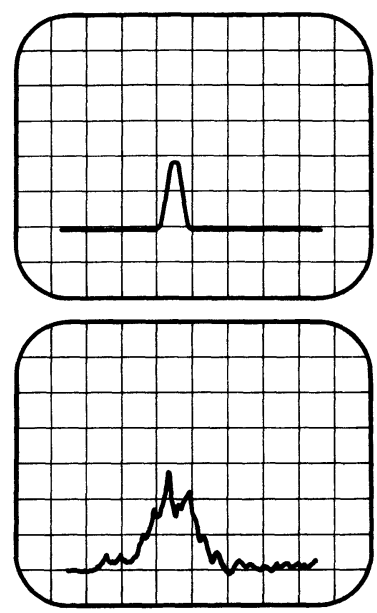

b)

Fig. 3. - Temporal and spectral characteristics of the amplified dye pulse. (a) Streak camera recording showing the 20 ps FWHM. (b) Spectrum of two amplified dye pulses; top : with the two grating assembly; bottom : with a single Littrow mounted $(2400 \mathrm{gr} / \mathrm{mm})$ grating (the spectrometer dispersion has been divided by two).

If one considers that some increase of both the spectral width and the pulse duration is due to the limited resolution of both the camera and the spectrometer, this result is in good agreement with the theoretical value of this product corresponding to Fourier limited pulses, which range from 0.441 to 0.6 depending of the actual pulse shape [2]. Statistical fluctuations of the measured pulse duration were of the order of the camera resolution.

Pulse lengths were measured in four different situations : with two different pumping pulse durations (20 ps and $60 \mathrm{ps}$ ), and with two different incidence on the $\mathrm{Gl}$ grating $\left(85^{\circ}\right.$ and $\left.89^{\circ}\right)$. When $20 \mathrm{ps}$ pulses are used the dye pulse duration does not depend on the incidence angle. When $60 \mathrm{ps}$ pulses are used, values of 25 ps and 30 ps were measured for respectively $85^{\circ}$ and $89^{\circ}$ incidence. If these differences are meaningful (they barely exceed our time resolution), they would seem to indicate that short pumping pulses determine the dye laser pulse duration; on the contrary, when long pumping pulses are used, the dye pulse duration is essentially determined by the dye oscillator characteristics. 
When lower incidence angles were used (trying to shorten the laser pulse), it resulted in wavelength instabilities which were observed for angles of $80^{\circ}$ and less. A $85^{\circ}$ incidence angle gives a perfectly stable wavelength, within our $10 \mathrm{GHz}$ accuracy.

No difference was noticed concerning the pulse duration when either the grating-mirror assembly or the double grating (with subtractive dispersion) assembly were used, if the total dispersion of the system was kept constant, although the latter could be thought to provide some compensation of the optical paths difference between the two extreme rays of the beam. This is due to the fact that this path difference depends only on the total dispersion and not on the detailed geometry of the system.

Tunability of this laser with rhodamine $6 \mathrm{G}$ was found to extend between 557 and $570 \mathrm{~nm}$. The divergence of the laser beam was measured to be $2 \times 10^{-3}$ rad (full angle).

Figure 4 presents a typical experimental result obtained with this laser. Three photon ionization of $\mathrm{Sr}$ around $560 \mathrm{~nm}$ shows many resonances due to either intermediate two photon resonances or to final autoionizing states. Three of them are shown on figure 4. The width of the longer wavelength one (the rightmost on Fig. 4) is at most of $50 \mathrm{GHz}$ and is certainly larger than the laser bandwidth. For such scanning applications, the $\mathrm{G} 2$ grating is rotated with help of a potentiometric motor driven by a LSI-11 computer.

\section{Conclusion.}

We have presented here a simple design of a synchronously pumped dye laser-amplifier system delivering fully Fourier limited pulses with a 20 ps duration. None of the problems classically encountered in nanosecond systems were met. This makes our system quite easy to align and to operate. Given the good quality of the beam, principally due to the use of longitudinal pumping, very high intensities can be

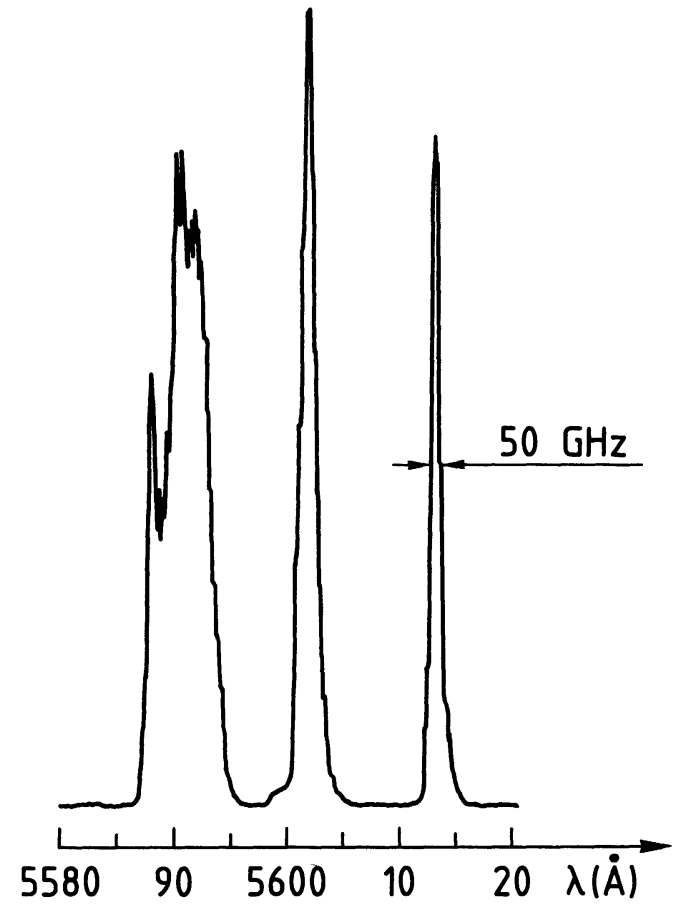

Fig. 4. - Typical experimental result obtained with our laser : resonance spectrum of the three photon ionization of $\mathrm{Sr}$.

obtained at the focus of a lens (of the order of $10^{12} \mathrm{~W} /$ $\mathrm{cm}^{2}$ ). This design represents a cost-effective, easy-touse alternative to the $\mathrm{CW}$ based lasers, which can be very useful whenever high intensity short pulses are needed.

\section{Acknowledgments.}

The authors would like to acknowledge the help of Claude Robine and Michel Bougeard in building most of the mechanical parts of this system, and Angel Sanchez for interfacing our system with the LSI-11 computer.

\section{References}

[1] Mocker, H. W. and Collins, R. J., Appl. Phys. Lett. 7 (1965) 270.

DeMaria, A. J., Stetser, D. A. and Heynaud, H., Appl. Phys. Lett. 8 (1966) 174.

[2] For a complete revue on Picosecond Dye Lasers see D. J. BradLeY, in Ultrashort Light Pulses, S. L. Shapiro editor (Springer Verlag, Berlin) 1977.

[3] Bradley, D. J. and Durrant, A. J. F., Phys. Lett. 27A (1968) 73.
[4] Wokaun, A., Liao, P. F., Freeman, R. R. and Storz, R. H., Opt. Lett. 7 (1981) 13.

[5] Littman, M. G., Opt. Lett. 3 (1978) 138.

[6] Cunin, B., Miehe, J. A., Sipp, B., Schelev, M. Ya., SERDUChENKo, I. N. and ThebaUlt, J., Rev. Sci. Instrum. 51 (1980) 103.

[7] Bradley, D. J. and Sibbett, W., Opt. Commun. 9 (1973) 17.

L'Huillier, A., Lompre, L. A., Mainfray, G. and Manus, C., J. Physique 44 (1983) 1247. 